\title{
Entretextos: Borges e Machado de Assis
}

Andréa Sirihal Werkema | UFMG

Resumo: A proposta deste artigo é fazer um breve exame de dois autores, Borges e Machado de Assis, em dois textos que discutem, em sua escrita, a presença inevitável de outras vozes na constituição da obra. Isto é, a presença de outros textos, a influência enquanto marca positiva e negativa. Palavras-chave: Influência; Intertextualidade; Semelhança; Diferença.

para a Ruth

Alguém propôs um método regressivo: Para localizar o livro $A$, consultar previamente um livro $B$, que indique o lugar de A; para localizar o livro $B$, consultar previamente um livro $C$, e assim até $O$ infinito... (J. L. Borges)

Influência: palavra anatematizada pela crítica (brasileira) contemporânea, preocupada em ser moderna, imparcial e politicamente correta. Até que ponto se justifica a mera mudança do termo influência por correlativos como influxo, ressonância, confluência, convergência; por que não a mudança da noção de influência, criação de novo conceito? Repensar a imagem da fonte, de onde mana a água original para os vários afluentes. Afluência? Alimentação? Transmissão? Intertextualidade? Observar o fenômeno, sem desviar os olhos daquilo que não se quer ver; não deixar de falar, ainda, da influência 
e do modo pela qual ela nos atinge em um país, e uma cultura, marcados pela importação de algo alheio, e sua transformação em algo próprio - e, de preferência, diferente. Sempre se quis a diferença? Em que momento ela passa a ser almejada, ou melhor, em que contextos? Em que tradições?

A proposta é fazer um breve exame de dois textos, dois autores, que discutem, em sua escrita, a presença inevitável de outras vozes na constituição da obra. Isto é, a presença de outros textos, a influência enquanto marca positiva e negativa. Sem procurar respostas definidas para as questões expostas, colocamo-nos à mercê das possíveis influências, no diálogo com outros críticos que já enfrentaram uma tal tarefa. Aqui, em dois rápidos e inconclusos comentários, sobre textos (nem tanto) diferentes, além da vontade de falar de questão tão problemática quanto ingrata (no sentido de que quase sempre se sairá perdendo), que transpareça, também, a vontade incessante de continuar lendo.

\title{
Da semelhança
}

\begin{abstract}
Se não me engano, as peças heterogêneas que enumerei se parecem com Kafka; se não me engano, nem todas se parecem entre si. Este último fato é o mais significativo. (J. L. Borges)
\end{abstract}

Relendo mais uma vez o texto de Borges, "Kafka y sus precursores", salta-nos novamente aos olhos o óbvio sempre esquecido de que tal texto se apresenta com ares de ficção; ficção crítica, é claro, mas à maneira borgiana de "fábula ou conto moral". ${ }^{2}$ Ao apontar em lugares diversos da literatura universal os possíveis precursores de Kafka, Borges estaria antes criando uma família literária na qual ele próprio se insere, já que os traços kafkianos descobertos na obra de um Kierkegaard ou de Han Yu dependem da leitura atenta de um Borges. A filiação de Kafka se dá a posteriori, é claro, mas inaugura no presente o que Borges chama de voz ou hábitos textuais kafkianos, ${ }^{3}$ certo tom ou inflexão, que, de forma paradoxal, criam, depois de Kafka, uma tradição que lhe é anterior e, diríamos, possibilita o ingresso de Borges em tal grupo, como legítimo

1. BORGES, 1974, p. 107-109.

2. NESTROVSKI, 1996, p. 104.

3. BORGES, 1974, p. 107. 
descendente de seu precursor Kafka. Num belo exercício eliotiano de fundação de sua própria tradição, Borges afeta a princípio não reconhecer em Kafka qualquer semelhança com outros autores; logo, a partir da leitura do próprio Kafka, sente-se apto a indicar autores que lhe seriam aparentados. É claro que tal movimento só se faz possível pela existência do leitor Borges, conhecedor de todos os precursores que cita, e se faz possível através da moldura ficcional utilizada para, kafkianamente, despistar, ou esfumaçar as certezas de um ensaio crítico formal, em oposição diametral aos contos falsamente crítico-historiográficos do próprio Borges. Em nossa rápida leitura do enigma crítico de Borges, importanos considerar alguns dos aspectos aí apresentados que contribuem para pensar ainda uma vez a espinhosa questão da influência na literatura.

O primeiro e óbvio aspecto diz respeito à semelhança encontrada por Borges nos vários textos que aponta: às vezes de "forma", às vezes de "tom", o parentesco com Kafka mostra-se nos enredos, nos temas e nos procedimentos de Browning, Bloy ou Zenón. "Em cada um destes textos está a idiossincrasia de Kafka, em grau maior ou menor, mas se Kafka não houvesse escrito, não a perceberíamos; isto é, não existiria." ${ }^{4}$ Os textos seriam diferentes entre si, podendo ser reunidos apenas a partir de um ponto referencial, a "idiossincrasia" kafkiana. Ou seja, mais uma vez, o que realmente decide na reunião de tantos e diferentes autores seria exatamente a diferença, ou aquilo mais específico de Kafka, destacado pela leitura atenta de Borges, que reconhece em Kafka algo de sua própria obra: a idiossincrasia ${ }^{5}$ borgiana estava prefigurada em Kafka, ou, se não fosse Borges, não teríamos percebido (não teria existido) tal semelhança? Em suma: a semelhança vista por Borges entre os textos citados transforma-se rapidamente na diferença encontrada em cada texto, em relação uns aos outros e em relação ao texto de Kafka.

4. BORGES, 1974, p. 109 (sempre que citamos este texto, traduzimos).

5. Cf. verbete "idiossincrasia": "constituição individual, em virtude da qual cada indivíduo sofre diferentemente os efeitos da mesma causa"; "qualquer detalhe de conduta peculiar a um indivíduo determinado e que não possa ser atribuído a processos psicológicos gerais, bem conhecidos." MICHAELIS, 1998, p. 1123.

6. Seria interessante lembrar aqui as categorias de "obra visível" e "obra invisível" pensadas pelo próprio Borges em seu famoso "Pierre Menard, autor do Quixote". BORGES, 1989, p. 29-38. 
Outro aspecto que nos interessa é a formação, via palavra, no próprio corpo do ensaio de Borges, de uma pequena biblioteca virtual, procedimento típico do autor, que, neste caso, aponta ironicamente para uma biblioteca kafkiana e não borgiana. Aspecto ficcional por excelência, já que a estratégia usada por Borges nos faz seguir o trajeto de Kafka, em sua transformação de precursores em descendentes, desviando nossa atenção da trajetória borgiana tão aparente na estrutura que constitui o ensaio. Borges nos joga de forma abrupta no momento presente, ao mostrar que o texto de Kafka, modificador do passado e do futuro, é criador de uma tradição atemporal de leitura - leitura feita por Borges, nesse caso, sendo que cada leitor-escritor-crítico será capaz de operar a criação de sua própria tradição. A pequena biblioteca kafkiana, escolhida a dedo por Borges, é metonímia das várias tradições prontas a serem fundadas - e não apenas resgatadas, a partir dos elementos comuns entre seus autores, como parecia querer Eliot em seu famoso "Tradição e talento individual". ${ }^{7}$ Nesse jogo entre individualidade e tradição, Borges parece ultrapassar seu precursor Eliot por orientar a sua formação de um corpus literário a partir do centro irradiador da diferença: Kafka, "tão singular como o fênix", espalha sua VOz por "textos de diversas literaturas e de diversas épocas". 8 existência simultânea de toda a literatura, prevista tanto por Eliot quanto por Borges, aponta novamente para a idéia da biblioteca, em cujas estantes convivem as mais diversas escritas das mais diversas épocas, em diálogo incessante. Tudo, em uma biblioteca, é simultâneo, quando visto pelos olhos de um leitor, que passa, de forma aparentemente indiscriminada, de um livro para outro.'

O que nos leva ao terceiro aspecto que gostaríamos de comentar, ou seja, a noção propriamente de influência como Borges a vislumbra em seu ensaio. "No vocabulário crítico, a palavra precursor é indispensável, mas era

7. ELIOT, 1989, p. 38: “(...) não apenas o melhor mas também as passagens mais individuais de sua obra podem ser aquelas em que os poetas mortos, seus ancestrais, revelam mais vigorosamente sua imortalidade."

8. BORGES, 1974, p. 107.

9. Veja-se a contrapartida ficcional-crítica de Borges sobre os livros de "A Biblioteca de Babel": "Esse pensador observou que todos os livros, por diversos que sejam, possuem elementos iguais: o espaço, o ponto, a vírgula, as vinte e duas letras do alfabeto. Também alegou um fato que todos os viajantes confirmaram: Não há, na vasta Biblioteca, dois livros idênticos." BORGES, 1989, p. 65. 
necessário purificá-la de toda conotação de polêmica ou de rivalidade. O fato é que cada escritor cria seus precursores." Ao usar os termos "polêmica" e "rivalidade", Borges parece nos dar pistas de sua visão do fenômeno da influência. Tais termos apontam para uma relação rancorosa entre precursor e discípulo, ou descendente literário. Borges reivindica um sentido puro, limpo de rancores para o termo precursor, e, por extensão, parece querer dizer que a influência, enquanto elemento constitutivo da criação literária, deve dar-se fora dos padrões tradicionais de julgamento de valor. Mesmo concordando com Borges na procura de outros valores que não os da literatura comparada tradicional (centro e periferia político-culturais, passado e presente), parece-nos claro que o apagamento da disputa e da rivalidade quando da inserção de um autor em um corpus delimitado é tarefa impossível; por outro lado, é através da polêmica criada no ato mesmo dessa inserção que se torna possível a mudança no elenco de valores para o julgamento da obra literária. A criação literária seria por natureza agonística, colocando em contínuo choque as forças da influência e da individualidade - que gostaríamos de resgatar como instância fundamental no processo criativo, em oposição a Eliot e ao próprio Borges. ${ }^{11}$ A exigência de uma noção de precursor da qual se filtrasse qualquer conflito individual trai uma certa ambivalência de Borges no lidar com seu legítimo precursor, Kafka, e seus possíveis aparentados. ${ }^{12}$ Tal ambivalência já está expressa na própria natureza ficcionalizante do ensaio, que, ao afirmar, sugere, ao mesmo tempo, seu caráter hipotético. ${ }^{13}$ Por outro lado, e para além de toda a sua universalidade literária, estamos ainda falando de um escritor argentino - condição que traz em si marca inegável de diferença, e se traduz, muitas vezes, em assimilação agressiva - polêmica - de possíveis influências. Nesses termos, a individualidade (ou a pluralidade) dos homens não se apaga facilmente; importa antes a maneira como cada escritor cria seus precursores, ou seja, como cada indivíduo-escritor

10. BORGES, 1974, p. 109.

11. "A evolução de um artista é (...) uma contínua extinção da personalidade." ELIOT, 1989, p. 42; "Nesta correlação, nada importa a identidade ou a pluralidade dos homens." BORGES, 1974, p. 109. Notese a força anti-romântica de tais argumentos.

12. Cf. NESTROVSKI, 1996, p. 106.

13. Cf. os termos ambíguos usados no início do ensaio de Borges: "Eu premeditei alguma vez um exame dos precursores de Kafka." BORGES, 1974, p. 107. 
se insere na tradição que escolheu, ou seja novamente, como tal sujeito trabalha, em seu próprio texto, as influências recebidas das mais diversas leituras quebrando as hierarquias centro/periferia, passado/presente e afirmando a possível passagem periferia/centro, presente/futuro. Esse primeiro passo, instalação de uma rua literária de mão dupla, seria seguido da já citada simultaneidade literária, que ocuparia o lugar da continuidade, favorecedora da associação de valores positivos aos textos ditos "primeiros" e negativos aos chamados textos "segundos".

Borges "desvia nossa leitura" de Kafka; em termos lógicos, portanto, Borges acaba por "criar" Kafka. Tal procedimento só se torna possível pela admissão (polêmica e ironizada pela ficção borgiana) da influência-presença de Kafka em sua obra. O desejo de reconhecer e examinar os precursores de Kafka mostra a Borges muito de sua própria voz. Para nós, leitores de Kafka e Borges, fica claro que ambos convivem na simultaneidade da mesma biblioteca, lado a lado talvez na mesma estante.

\title{
Da diferença negada
}

\begin{abstract}
A fama do Pestana dera-lhe definitivamente o primeiro lugar entre os compositores de polcas; mas o primeiro lugar da aldeia não contentava a este César, que continuava a preferir-lhe, não o segundo, mas o centésimo em Roma. (Machado de Assis)
\end{abstract}

Do conto de Machado de Assis, "Um homem célebre", ${ }^{14}$ importanos reter primeiro o fato de que estamos agora em águas totalmente ficcionais. Nem por isso menos críticas. De fato, o conto é um dos textos que melhor problematizam a questão da influência e da originalidade na cultura brasileira e "periférica" por extensão. Machado encena mesmo (através de um levemente maldoso narrador em terceira pessoa) o agon criativo do compositor Pestana, em constante sofrimento por não ser capaz de criar obra que se inclua entre as de seus ídolos musicais, Mozart, Beethoven, Bach, Schumann etc. Estes se enfileiram, em seus retratos encaixilhados, ao lado do retrato do pretenso pai de Pestana, um padre que o educara e lhe ensinara música. A analogia é óbvia, e importante para pensarmos a trajetória da relação escamoteada de "paternidade" entre Pestana e suas obras efetivas - as tão lamentadas polcas.

14. MACHADO DE ASSIS, 1997, p. 497-504. 
As polcas nascem-lhe com facilidade: "Compunha só, teclando ou escrevendo, sem os vãos esforços da véspera, sem exasperação, sem nada pedir ao céu, sem interrogar os olhos de Mozart. Nenhum tédio. Vida, graça, novidade, escorriam-lhe da alma como de uma fonte perene" . ${ }^{15}$ Sem esforço aparente, de forma natural; não seria exagero dizer que as polcas nascem-lhe de acordo com um estereótipo romântico, vindas do âmago insondável de seu criador, emanação do divino - fatalidade - que subsiste no humano. Esbarramos no mistério criativo que constitui o personagem Pestana, pois o narrador nunca nos informa de onde provém o "frêmito particular e conhecido" que antecede a composição das polcas. A partir de que instâncias nasceriam? Do nada, ganhando acabamento na hora mesma de sua criação? O cerne do personagem Pestana, seria, portanto, sua "contradição criadora", ${ }^{17}$ pois o músico não quer ver em si as influências óbvias de seus amados mestres, se elas levam-no a compor dentro de um gênero menor, popular. Pestana aceitaria compor como Mozart ou Chopin dentro dos cânones clássicos, da música erudita - o que chega a tentar várias vezes. O seu fracasso, aliás, se dá porque, ao tentar compor como Chopin, compõe efetivamente uma peça de Chopin, o que lhe traz uma dolorosa sensação de imitador sem originalidade, epígono. ${ }^{18}$ Já reconhecer em si o paradoxo do criador original, que trabalha as mesmas influências clássicas na composição das polcas, seria pedir demais ao melancólico Pestana. O músico não vê, em seu processo criativo, nas malhas da influência, o trabalho de transformação das referências eruditas em novas formas, nesse caso as polcas, gênero musical extremamente popular no Brasil da segunda metade do XIX (que desembocaria no nacionalíssimo chorinho); importa a Pestana a sua inclusão em cânone

15. MACHADO DE ASSIS, 1997, p. 499.

16. MACHADO DE ASSIS, 1997, p. 502.

17. Expressão cunhada por Fausto Cunha em texto sobre Álvares de Azevedo, portador de uma contradição entre sua postura crítica e sua prática poética, segundo o autor. Cf. CUNHA, 1971, p. 113-117.

18. Não há aqui, note-se, a irônica e vingativa atitude do narrador de Borges ao proclamar o Quixote de Menard como sua obra imortal, heróica. Há o sofrimento, ou melhor, a agonia de se estar eternamente "entre a ambição e a vocação". Cf. MACHADO DE ASSIS, 1997, p. 502. 
erudito e não-popular, uma perpetuação das hierarquias dos gêneros musicais, e não uma quebra de tais hierarquias pela admissão de um gênero novo. ${ }^{19}$

Pestana não percebe sua existência simultânea à dos compositores de sua galeria musical; separou-se deles, encaixilhou-os, de forma que o idealinatingível passou a ser mera fonte de dor, porque inalcançável - em vez de servir de motivo para a criação, para o movimento incessante das formas se transformando em novas formas: o "tornar às velhas fontes, donde lhe não manava nada" opõe-se a "vida, graça, novidade, [que] escorriam-lhe da alma como de uma fonte perene." 20

O estereótipo de Romantismo aqui lembrado faz-se significativo ao lembramos o lugar central que as noções de "originalidade" e "inspiração" ocuparam neste movimento. Pensa-se ainda no artista romântico como grande criador ex nibilo, cuja obra nasceria fora de qualquer relação com seus antecessores ou coetâneos. ${ }^{21}$ A um tal estereótipo contraporíamos duas teorias românticas da criação: uma teoria expressivista e outra reflexiva (sem fazer aqui o julgamento valorativo das teorias expostas).

Em poucas palavras, a teoria expressivista da obra de arte romântica estabeleceria uma ligação direta entre a obra e seu criador na medida em que a primeira constituir-se-ia na expressão direta, ou tradução dos sentimentos do autor. A obra seria um prolongamento da subjetividade autoral e portanto sempre sincera, portadora de uma verdade encontrada nos elementos sentimentais que a integram. Dilui-se ao máximo a separação entre vida e obra, cria-se a idéia de paternidade artística, pois a obra é filha dos sentimentos do indivíduo-

19. Conferir o que diz o próprio Machado de Assis em crônica de 1887, escrita em quadras: "Mas a polka? A polka veio/De longes terras estranhas,/ Galgando o que achou permeio/Mares, cidades, montanhas/Aqui ficou, aqui mora;/Mas de feições tão mudadas,/Que até discute ou memora/Cousas velhas e intrincadas." MACHADO DE ASSIS, 1938, p. 317. Não custa lembrar que a polca, vinda do leste da Europa, adquiriu no Brasil ritmo peculiar e dançante - daí para Machado o gesto nacional de apropriar-se da cultura estrangeira em tradução via popularidade.

20. MACHADO DE ASSIS, 1997, p. 500, p. 499.

21. Veja-se o belo texto de NESTROVSKI, 1996a, p. 143-148, sobre a criação em Beethoven: "uma das marcas do 'criador' é que ele se torna o precursor de si mesmo: que ele absorve e transforma sua própria obra e se constitui, assim, numa nova tradição ou cânone individual." 
criador. O expressivismo romântico, largamente difundido nas histórias literárias mais tradicionais, apagaria a criticidade inerente à criação artística; por outro lado, fundamenta essa mesma criação ao dar-lhe uma fonte: os sentimentos do autor. Não se cria do nada; é preciso sentir para depois criar.

Opõe-se a uma tal teoria as concepções do Romantismo reflexivo: a obra ainda liga-se diretamente ao autor, na medida em que é fruto da reflexão ocorrida dentro das instâncias subjetivas que constituem um indivíduo-autor. Note-se a matriz mais filosófica da própria noção de subjetividade que pensa a si própria, através da obra de arte. A criação se dá a partir da continuada reflexão do artista sobre suas formas e meios; sobre a tradição que o constitui e suas novas configurações a partir do olhar romântico. "Romantizar", dentro dessa teoria, é acercar-se das obras de arte com olhos românticos, buscá-las para o âmbito da reflexão.

No conto de Machado de Assis, nem uma das duas teorias românticas parece fundamentar os processos criativos de Pestana, permanecendo o estereótipo. No silêncio do narrador em relação às fontes criativas de Pestana acabamos por enxergar a ironia do autor. Pestana negaria até a morte a presença de seus autores preferidos (sua biblioteca musical), ou de seus sentimentos mais íntimos, nos meneios dançarinos de suas polcas; estas seriam fruto da fatalidade que o persegue - a diferença. Voltemos a uma outra preocupação romântica: a configuração de novos gêneros no interregno do erudito e do popular, entre o alto e o baixo, na mistura de elementos díspares como marca da própria obra de arte. Libertar um Mozart ou um Bach de sua circunscrição temporal e de gênero; assegurar-lhes a possibilidade de continuar vivendo em uma obra de outra época, e de outro gênero - esta seria uma cruzada genuinamente romântica. Em Machado de Assis, encontramos, portanto, a intuição genial de que a visada romântica assume implicações quase políticas num país como o Brasil. A apropriação romântica traria para nosso âmbito um universalismo radical - nas polcas de Pestana viveriam, ao mesmo tempo, todos os autores de sua galeria musical, além da brasilidade - "musa de olhos marotos e gestos arredondados, fácil e graciosa" ${ }^{22}$ - que tanto mal lhe fazia.

Movimento dito criador da própria noção de brasilidade, o Romantismo brasileiro seria emblemático de uma literatura criada no embate

22. MACHADO DE ASSIS, 1997, p. 500. 
entre influência e originalidade; desde a aceitação por vezes submissa de modelos ditos superiores até a negação agressiva das leituras formadoras de uma consciência crítica nacional. Na figura sofrida e romântica de Pestana, que nega sua verdadeira obra até a morte, Machado de Assis personificou a imagem do criador brasileiro, quiçá latino-americano, "alucinado, mortificado, eterna peteca entre a ambição e a vocação..." Não acontece, para Pestana, nenhuma quebra de hierarquia, seja nos gêneros musicais, seja nos valores da música européia em relação a sua música brasileira. A não ser momentaneamente, Pestana não vê aquilo que ama (a semelhança) na música que compõe. Ele só vê a diferença, e nega-a.

Atentemos para o fato de que a diferença nem sempre se coloca como elemento positivo para o artista da "periferia" cultural. Muitas vezes ela é estigma do não-pertencimento em uma tradição. A intuição machadiana, repetimos, é genial, porque percebe que, para aceitar a diferença enquanto engendrada a partir da tradição, Pestana teria necessidade da reflexão sobre as formas da arte, no caso a música. Num segundo momento, Pestana passaria da reflexão sobre a obra alheia ("Releu e estudou o Requiem deste autor [Mozart]" para a reflexão sobre sua própria obra - o que não se dá nunca, já que o personagem se nega muitas vezes até a ouvir suas polcas. Veja-se que a tradição já está escolhida (fundada?) e internalizada em Pestana, mas a ausência da reflexão leva-o a ser enganado pela memória ("velha cidade de traições" ${ }^{25}$ ) e a confirmar em si mesmo um estereótipo de artista "alucinado" - excluído de uma tradição - "mal consigo mesmo".

23. MACHADO DE ASSIS, 1997, p. 502.

24. MACHADO DE ASSIS, 1997, p. 503.

25. MACHADO DE ASSIS, 1997, p. 502.

26. MACHADO DE ASSIS, 1997, p. 504. Em termos borgianos, portanto, Pestana não chega nunca a se criar enquanto artista, a despeito de sua obra: ele não vê os traços "invisíveis" da tradição no tecido de suas polcas. Releia-se também a nota 21 deste artigo: Pestana não se torna "precursor de si mesmo". 
Abstract: The present essay proposes a brief reading of two authors, Borges and Machado de Assis, in two texts that are able to discuss the inevitable presence of strange voices inside the work constitution, or, in other words, the presence of various texts in one text, the question of influence as a positive or negative feature.

Key words: Influence; Intertextuality; Similarity; Difference.

\section{Referências Bibliográficas}

BORGES, Jorge Luis. Kafka y sus precursores. In: Obras completas. Buenos Aires: Emecé, 1974

BORGES, Jorge Luis. Fiç̧ôes. Trad. Carlos Nejar. São Paulo: Globo, 1989.

CUNHA, Fausto. Álvares de Azevedo ou a contradição criadora. In: O Romantismo no Brasil. Rio de Janeiro: Paz e Terra, 1971.

ELIOT, T. S. Tradição e talento individual. In: Ensaios. Trad. Ivan Junqueira. São Paulo: Art, 1989.

MACHADO DE ASSIS. Crônicas. Rio de Janeiro: W. M. Jackson, 1938. v.4

MACHADO DE ASSIS. Um homem célebre. In: Obra completa. Rio de Janeiro: Nova Aguilar, 1997. V. II.

MICHAELIS: moderno dicionário da língua portuguesa. São Paulo: Companhia Melhoramentos, 1998.

NESTROVSKI, Arthur. Influência. In: Ironias da modernidade. São Paulo: Ática, 1996.

NESTROVSKI, Arthur. "Gerar um novo mundo do nada". In: Ironias da modernidade. São Paulo: Ática, 1996a. 